\title{
A study on morbidity profile of lignite miners in western India
}

\begin{abstract}
:
Background: Mining is a hazardous occupation in which workers are exposed to adverse conditions. In India, there are nine working lignite mines, producing about 30 million tons annually. The mines are located in the states of Tamilnadu, Rajasthan and Gujrat. Objective: The present study was carried out in a lignite mine in India to determine the health status of the miners. Methods: 143 workers engaged actively in mining activities were included. The health status of the employees was evaluated by well defined medical questionnaire along with pulmonary function test (PFT) and Audiometry. Result: Findings of the study showed poor literacy rate amongst the miners. Pulmonary impairment was present in $11.88 \%$ and noise induced hearing impairment in about $12.15 \%$ of the miners. Conclusion: The study findings indicate the need for regular health checkups, health education, personal protective devices and engineering control.
\end{abstract}

Key Words: Lignite mine, miners, pulmonary impairment, hearing impairment.

\section{Introduction}

Mining is one of the major occupations in India involving large number of work force which is going to grow in future. Mining being a hazardous occupation, workers are exposed to adverse conditions involving physical labour, stress and environmental pollutants like dust, noise, heat, vibration, poor illumination, radiation etc,. Lignite, often referred to as brown coal, is the lowest rank of coal and used almost exclusively as fuel for steam-electric power generation. It is brownish-black and has a high inherent moisture content, sometimes as high as $66 \%$, and very high ash $50 \%$ content compared with bituminous coal. It is also a heterogeneous mixture of compounds for which no single structural formula will suffice. It is often burned in power stations constructed very close to any mines. [1] In India, there are nine working lignite mines. The mines are located in the states of Tamilnadu, Rajasthan and Gujrat. In year 2005-06, the production of lignite was about 30 million tons. [2]

The present study was carried out in a lignite mine to study the health status of the miners.

\section{Methods}

The present study was carried out in a lignite mine in western India. 143 workers engaged actively in mining activities were included.

The health status of the employees was evaluated by well defined medical questionnaire based on modified British Medical
Research Council. [3]

A brief family and personal history, work history, present and past medical status, symptoms and signs related each body system etc. were noted in medical questionnaire.

Spirometry of 141 miners out of 143 was carried out by Cosmed Pony Graphic 4.0 by following standard procedure. [4] Three readings of forced vital capacity (FVC) and forced expiratory volume in one second (FEV1) were obtained for each worker and the best reading was taken for reporting and analysis. The results were interpreted as normal Spirometry, obstructive, restrictive or combined impairment on the basis of the performance of the subject. Predictive FVC was calculated by predictive equation of Kamat et al. [5] Measured FVC $<80 \%$ of predictive value is termed as Restrictive impairment (RI), FEV1/ FVC $<70 \%$ is termed as Obstructive Impairment (OI), and combination of $\mathrm{RI}$ as well as $\mathrm{Ol}$ is termed as combined impairment.[6]

Evaluation of 140 subjects for hearing capability was measured for air conduction by audiometric test with the help of Elkon eda 3N3 multi diagnostic audiometer MH 2K2 189. The audiometry was conducted in a small closed room having minimal background noise for sound frequencies ranging from $0.5 \mathrm{KHz}$ to $8 \mathrm{KHz}$ and the minimum intensity for measurement was from $15 \mathrm{~dB}(\mathrm{~A})$. The subject was made to sit comfortably on a chair and thoroughly briefed about audiometric test. Earphones were 
put on his ears and a hand switch was given to him to note his response to various sound intensity and frequency. He was instructed to press the switch as soon as he hears a faint sound. The responses of the subject were noted in the Elkon audiogram data sheet. [7] Audiogram of mine workers were evaluated as per WHO recommendations for classification on the basis of pure tone audiogram evaluating the thresholds of hearing for frequencies of 500, 1000, 20004000,6000 and $8000 \mathrm{~Hz}$. The principle criteria for diagnosis of occupational NIHL was (i) History of exposure to excessive noise levels (ii) Bilateral sensor neural hearing loss showing similar pattern in both ears (iii) The difference between two ears should not exceed $15 \mathrm{~dB}$ at 500,1000 and $2000 \mathrm{~Hz}$ and $30 \mathrm{~dB}$ at 3000,4000 and $6000 \mathrm{~Hz}$. (iv) Sign of "notching" in the audiogram at high frequencies of 3000,4000 or $6000 \mathrm{~Hz}$ with recovery at $8000 \mathrm{~Hz}$. (8)

\section{Results}

This Personal information about the subjects like age, height, weight, body mass index (BMI), smoking and tobacco chewing habit are given in [Table1].

\section{Table 1: Personal information of miners}

\begin{tabular}{|l|l|}
\hline Parameters & Miners $(\mathrm{N}=143)$ \\
\hline Age $(\mathbf{y r})^{*}$ & $33.02 \pm 9.99$ \\
\hline Height $(\mathbf{c m})^{*}$ & $166.68 \pm 6.02$ \\
\hline Weight $(\mathbf{k g})^{*}$ & $61.61 \pm 10.50$ \\
\hline BMI $^{*}(\mathbf{k g} / \mathbf{m} 2)$ & $22.13 \pm 3.40$ \\
\hline Smokers & $24(16.78 \%)$ \\
\hline Non-smokers & $119(83.21 \%)$ \\
\hline Tobacco chewers & $33(23.07 \%)$ \\
\hline
\end{tabular}

$* \mathrm{X} \pm \underline{\mathrm{Sd}}$

The educational status is depicted in [Table 2], showing about $23.77 \%$ illiteracy amongst miners.

Table 2: Educational status of the miners

\begin{tabular}{|l|l|}
\hline Education & Miners $(\mathrm{N}=143)$ \\
\hline Illiterate & $34(23.77 \%)$ \\
\hline Primary & $58(40.55 \%)$ \\
\hline Secondary & $35(24.47 \%)$ \\
\hline University & $16(11.18 \%)$ \\
\hline
\end{tabular}

Figures in parenthesis indicate percentage

The subjects exposed to mining activities are further sub grouped depending upon there occupational exposure is shown in [Table 3].
Table 3: Number of miners according to their work exposure

\begin{tabular}{|l|l|}
\hline Duration (years) & Miners ( N = 143) \\
\hline $\mathbf{0 ~ - ~ 1 0 ~}$ & $100(69.93 \%)$ \\
\hline $\mathbf{1 1}-\mathbf{2 0}$ & $30(20.97 \%)$ \\
\hline $\mathbf{2 1}-\mathbf{3 0}$ & $11(7.69 \%)$ \\
\hline $\mathbf{3} \mathbf{3 0}$ & $2(1.39 \%)$ \\
\hline
\end{tabular}

Figures in parenthesis indicate percentage.

Significantly higher numbers of miners, about $70 \%$ have occupational exposure in between $0-10$ years and $21 \%$ in $11-20$ yrs. Lung function test carried out in miners showed about 11.88 $\%$ prevalence of restrictive impairment [Table 4].

\section{Table 4: Pulmonary function test results amongst miners}

\begin{tabular}{|l|l|}
\hline PFT & Miners ( N=141) \\
\hline Normal & $117(81.81 \%)$ \\
\hline Obstructive impairment & $5(3.49 \%)$ \\
\hline Restrictive impairment & $17(11.88 \%)$ \\
\hline Combined impairment & $2(1.39 \%)$ \\
\hline
\end{tabular}

Figures in parenthesis indicate percentage.

Audiometry examinations reveled about $12 \%$ of the miners had noise induced hearing impairment, shown in [Table 5].

Table 5: Hearing impairment in the miners.

\begin{tabular}{|l|l|}
\hline Hearing Status & Miners ( $=140)$ \\
\hline Normal & $123(87.85 \%)$ \\
\hline $\begin{array}{l}\text { Noise Induced Hearing Impair- } \\
\text { ment }\end{array}$ & $17(12.15 \%)$ \\
\hline
\end{tabular}

The observed morbidity pattern amongst the miners is shown in [Table 6].

Table 6: Morbidity pattern in the miners.

\begin{tabular}{|c|c|}
\hline Morbidity & Miners ( $N=143$ ) \\
\hline \multicolumn{2}{|l|}{ Cardiovascular System } \\
\hline Hypertension & $9(6.29 \%)$ \\
\hline \multicolumn{2}{|l|}{ Musculoskeletal system } \\
\hline Backache & $4(2.79 \%)$ \\
\hline Joint pain & $11(7.69 \%)$ \\
\hline \multicolumn{2}{|l|}{ Metabolic Disorders } \\
\hline Diabetes & $1(0.69 \%)$ \\
\hline \multicolumn{2}{|l|}{ Respiratory System } \\
\hline Pulmonary Tuberculosis & $4(2.79 \%)$ \\
\hline
\end{tabular}

The prevalence of hypertension was $6.29 \% .10 .48 \%$ of miners showed musculoskeletal symptoms. Prevalence of pulmonary tuberculosis was about $2.79 \%$ amongst miners. 


\section{Discussion}

There are very few studies carried out among the Indian miners pertaining to the health status. Most of the studied has carried out to show the prevalence of pneumoconiosis mainly silicosis. The literacy rate amongst miners was found poor, illiteracy and primary level education seen to the extent of $64 \%$. Smoking was seen in $16.78 \%$ of miners, which is an important predisposing factors in augmentation of lung disease.[9] Australian longitudinal study found that smoking and occupational exposure to lignite dust were significantly associated with a decline in lung function. [10] Another study in Greece revealed a possible interaction between smoking and occupational exposure to lignite dust regarding the impact on lung function. [11] Present study showed $11.88 \%$ restrictive lung function impairment in the miners that might be attributed to lignite dust and smoking habit. The presence of restrictive impairment could represent an early biological response to smoking and occupational exposures, which may further result in gross loss of pulmonary function in future. Musculoskeletal symptoms were prevalent in miners may be attributed to heavy physical work and associated machinery vibration.

Prolonged exposure to hazardous noise levels over a period of several years with no hearing protection will almost always cause permanent damage to the auditory nerve and almost certainly affects an individual's quality of life. Generally, the greater the noise exposure, the more rapid the loss. [12]

National institute of occupational safety and health (NIOSH), USA reported about $20 \%$ noise induced hearing loss (NIHL) in coal operators, $27 \%$ in metal operators, $12 \%$ in stone operators and $7 \%$ each in non metal operators and sand and gravel operators, thus showing hearing impairment as one of the major occupational hazard related with mining.[13] A recent $\mathrm{NIOSH}$ analysis of audiograms showed that by age 50 about 90 percent of coal miners and 49 percent of metal/nonmetal miners had hearing impairment. By contrast, only 10 percent of the population that experienced non occupational exposure to noise had any hearing loss by age 50. [12] In the present study amongst lignite miners the noise induced hearing impairment was about $12 \%$. The majority of miners are in the $0-10$ years of exposure group, so as the work exposure and the age of the miners will increase the risk of further progression of hearing loss will increase.

This is probably the first study among lignite miners to illustrate the morbidity pattern, in India. More elaborative studies are required to know the detailed morbidity pattern amongst Indian miners. There is some evidence that offering programs to reduce exposures to occupational hazards may stimulate workers participation in health promotion activities. [14] An effective anti-smoking policy in worksite should integrated into a broader context of occupational health and safety promotion. Regular periodical health examination, health education and use of personal protective equipment amongst the workers have to be encouraged. Implementation of engineering measures to control exposure levels will significantly benefit the health and productivity of the miners. Enforcing legal regulations especially regarding environmental monitoring will ensure better working condition. Awareness regarding prevention of health hazards in mining industry should be created among the mine management by conducting training and education programmes.

\section{References}

1. http://en.wikipedia.org/wiki/Lignite (assessed on 2 July 2014)

2. Indian bureau of mines. Indian mineral yearbook 2006. Nagpur (India): IBM press; 2007. pp. 24.1-24.28

3. British Medical Research Council. British Standardized questionnaires on respiratory symptoms. Br Med J (Clin Res) 1976;2:1965-8.

4. Renzetti $A D$ Jr. Standardization of spirometry. Am Rev Respir Dis 1979; 119: 831-8.

5. Kamat SR, Sarma BS, Raju VRK, Venkataraman C, Balkrishna M, Bhavsar RC, Kulkarni ST, Malhotra MS. Indian norms for pulmonary function. J Assoc Physicians India 1977; 25: 531-540.

6. James A, Interpretation of Pulmonary Function Test. http:// home.columbus.rr.com/allen/pft_interpretation.htm (accessed on 8 June 2008)

7. Niland J. Occupational hearing loss, noise, and hearing conservation. In: Zenz C, Dickerson O, Horvarth E, editors. Occupational Medicine. 3rd ed. St Louis Missouri: Mosby Publication; 1994. pp. 258-96.

8. Stig Arlinger. Manual Of Practical Audiometry Volume 1 (A.I.T.B.S Publishers and Distributor, New Delhi). 2004

9. Goren AI, Bruderman I. Effects of Occupational Exposure and Smoking on Respiratory Symptomatology and PFT in Healthy Panelists and COPD Patients. European J Epidem 1989; 5 (1): 58-64.

10. Finocchiro $C$, Lark A, Keating M, Ugony A, Abramson M. Does occupational exposure to brown coal dust cause a decline in lung function? Occup Environ Med 1997; 20: 642-5.

11. Drivas S, Rachiotis G, Vlastos FD, Zacharias C, Alexopoulos CG, Symvoulakis M, Vasiliou M, Bhrakis PK . Occupatiuonal exposure to lignite and impact on respiratory system among heavy industry personnel. Ind Health 2007; 45: 409-14.

12. Centers for Disease Control and Prevention. http://www.cdc.gov/ niosh/mining/pubs/pubreference/outputid919.htm (accessed on 5 July 2014 )

13. Centers for Disease Control and Prevention. http://www.cdc.gov/ niosh/mining/pubs/pdfs/iiahe.pdf (accessed on 5 July 2014 )

14. Sorensen G, Stoddard A, Ockene JK, Hunt NK, Yongstom R . Worker partcipation in an integrated health promotion health protection program: results from the well works project. Health educ Q 1996; 23:1. 